Pre-print of:

Cano E., Ramírez Barat B. (2018) Electrochemical Techniques for in situ Corrosion Evaluation of Cultural Heritage. In: Bastidas D., Cano E. (eds) Advanced Characterization Techniques, Diagnostic Tools and Evaluation Methods in Heritage Science. Springer, Cham

Originally published at: https://doi.org/10.1007/978-3-319-75316-4 2 


\title{
Electrochemical techniques for in-situ corrosion evaluation of Cultural Heritage
}

\author{
E. Cano, B. Ramírez Barat \\ National Centre for Metallurgical Research, CENIM-CSIC. Corrosion and Protection of Metallic \\ Materials for Cultural Heritage and Construction Research Group. Ave. Gregorio del Amo 8, \\ 28040 Madrid, Spain.
}

\begin{abstract}
Several analytical techniques can provide information about the elemental or molecular composition of metallic cultural heritage objects. But only electrochemical techniques can provide direct mechanistic and kinetic information of the corrosion process taking place on the metallic surface. While these techniques are routinely used in corrosion laboratories, their application for in-situ assessment of the corrosion of metallic cultural heritage is much less common. One of the main reasons for that is the difficulty of handling a liquid electrolyte on irregular, leaning and usually rough surfaces.
\end{abstract}

In this chapter, a short historic review of the use of electrochemical techniques in conservation science is presented, paying special attention to different approaches for solving the issues of in-situ measurements. A new gel polymer electrolyte (G-PE) electrochemical cell, specifically developed by our research group for its application on metallic cultural heritage, is explained. This cell overcomes some of the shortcomings of previous developments, and has shown to provide results comparable to a traditional liquid cell. Examples are presented of its use in the comparison of the performance of different acrylic coatings for bare or patinated bronze, or the follow-up of the restoration treatment underwent on the bronze sphinxes of the National Archaeological Museum in Madrid.

\section{Electrochemical techniques}

\subsection{Electrochemical techniques}

Corrosion is the main cause of deterioration of metallic cultural heritage. With the exception of those made in noble metals, any metal object in contact with its environment will corrode by an electrochemical reaction in which in the metal (M) oxidizes, giving off one or more electrons to another specie in the surroundings (Figure 1). Although it is an inevitable process, conservation science can help to restrain the velocity of the degradation and reduce the undesirable consequences through identification of the degradation causes 
(diagnosis), finding methods to slow down the degradation (treatment) and prediction of the evolution over time (prognosis). For this purpose conservation science requires a comprehensive approach. A global knowledge about the object is essential for the conservators to design the most appropriate conservation programme for each object. The analysis of meaning and values of the object, general condition, composition and structure through visual inspection, documentary resources and analytical techniques (XRF, Raman, XRD, SEM-EDX, LIBS etc.) are nowadays part of the conservator's routine work. But when dealing with metals, there is another question that has to be addressed, the corrosion process. Being corrosion an electrochemical process, electrochemical techniques provide a suitable tool for this purpose.

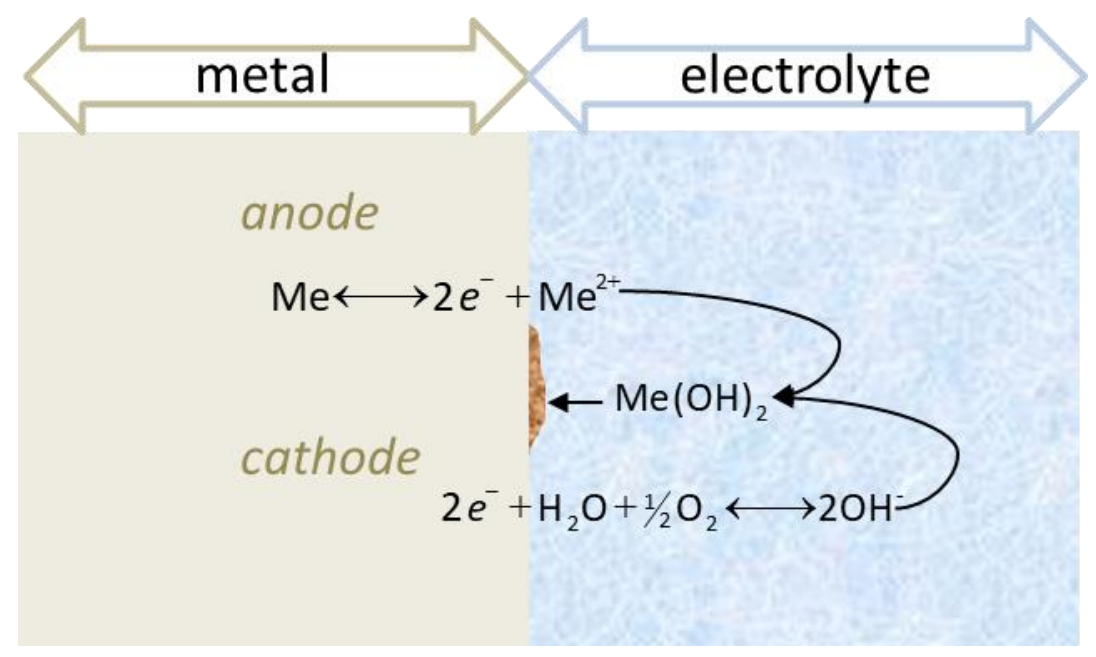

Figure 1 Typical corrosion mechanism of metals, in aerated neutral solution. The metal is oxidized and dissolved into the electrolyte, while the oxygen contained in it is reduced to hydroxyl ions, which precipitate with the metal ion as a hydroxide.

Electrochemical techniques are based in three parameters: potential $(E)$, current $(\mathrm{I})$ and time $(\mathrm{t})$. The combination of these parameters gives a broad range of techniques with different applications in analytics and diagnostic: polarization resistance (Rp), polarization curves (Tafel), voltammetry, potentiostatic and galvanostatic techniques, electrochemical noise (ECN), electrochemical impedance spectroscopy (EIS), etc. These techniques are widely used in research laboratories and industry for corrosion studies and evaluation of protection systems. Among them, EIS is the main technique used for corrosion and protection studies since the $80 \mathrm{~s}$. In addition to providing quantitative information of corrosion rates and information about the mechanisms, they offer very high sensibility and require relatively simple and inexpensive equipment.

In the field of metallic cultural heritage studies, despite these advantages electrochemical techniques are best known by metal conservators-restorers as a tool for restoration treatments ("electrolytic cleaning") and their use for corrosion 
and protection studies in metallic cultural heritage is more recent and far from being a routine method.

\subsection{EIS fundamentals}

EIS is based on the application of a small AC voltage (E) signal (usually $10 \mathrm{mV}$ ) to the system under study, and measuring the $\mathrm{AC}$ current (i) response for a certain frequency range (typically $10^{-3}-10^{5} \mathrm{~Hz}$ ). From the relation $\mathrm{E} / \mathrm{i}$, the impedance is obtained as a function of frequency.

$$
\begin{gathered}
\text { Signal: } E(t)=E_{0} \operatorname{sen}(\omega t) \rightarrow \text { Response: } I(t)=I_{0} \operatorname{sen}(\omega t+\varphi) \\
Z(t)=\frac{E(t)}{I(t)}=Z_{0} \frac{\operatorname{sen}(\omega t)}{\operatorname{sen}(\omega t+\varphi)}
\end{gathered}
$$

EIS spectra can be represented in different ways, being Bode and Nyquist plots the more common (Figure 2). Bode plots represent the impedance modulus, $|Z|$ or $Z_{0}$, and the phase shift, $\varphi$, vs the frequency in a logarithmic scale, and is particularly appropriate to represent large variations in the $Z$ values. A Nyquist plot is a representation of the impedance vector, with the imaginary part on the $y$-axis and the real part on the $x$-axis. This plot is preferred to present more clearly certain features such as diffusion effects.

Bode plot: $|Z|$ and $\varphi$ vs $\omega$

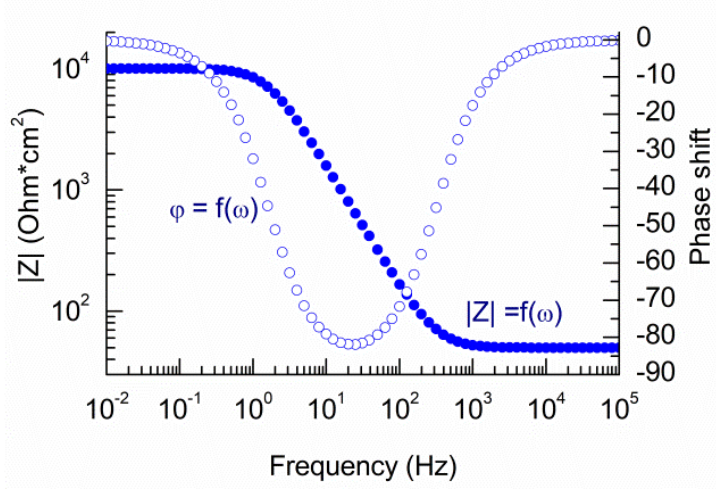

Nyquist plot: Zreal vs -Zimag

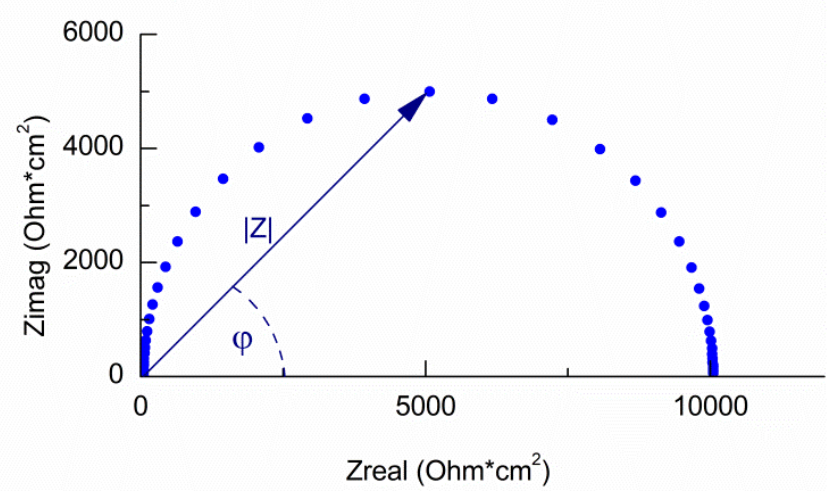

Figure 2 Typical representation of EIS spectra.

\subsection{Interpretation of EIS}

EIS is a very powerful technique that provides a lot of information on the electrochemical processes in the surface of the metal. However, extracting this information from experimental results is not a trivial task. Some simplistic interpretations, based on parameters such as the impedance modulus at low frequencies are commonly used and can be sufficient for comparison purposes 
in known systems [1]. This value is equivalent to the sum of the contribution to total impedance of all aforementioned elements and processes, thus it can be taken as a general estimation of the resistance of the system against corrosion.

In order to obtain in-depth information, EIS spectra are frequently interpreted using equivalent circuits which try to reproduce the electrical behavior of the system. In those circuits, parallel and series combinations of passive electrical elements such as capacitors and resistances are used to describe the different physical elements and processes in the system under study. Other elements specific for electrochemical systems, such as Constant Phase Elements (CPE) or Warburg impedance, are frequently employed. CPE are used in cases such as non-uniform coatings, surface roughness or inhomogeneous distributions of the current/potentials, which produce an electrochemical response departing from the behavior of an ideal capacitor. Warburg impedance is an element that models the impedance associated to diffusion (i.e. mass transfer) processes and is commonly used when the diffusion of species through the pores of the coating or corrosion products controls the corrosion rate.

While many circuits can be fitted to the experimental data, extracting useful information requires selecting a circuit which is physically meaningful. A typical example is presented in Figure 3 for a coating-metal system. $R_{e}$ represents the electrolyte resistance, while a capacitor $\mathrm{C}_{\text {coat, }}$, in parallel with a resistance, $\mathrm{R}_{\text {coat, }}$ model the capacitance and resistance of the protective coating in an ideal situation. If the coating is damaged or not completely protective then the circuit changes, and as the electrolyte reaches the metal surface through the pores and corrosion takes place, a new R-C pair appears. The corrosion process can be represented by a capacitor for the double layer capacitance, Coll, in parallel with the charge transfer resistance, $\mathrm{R}_{\text {tc. }}$ In this case, $\mathrm{C}_{\text {coat }}$ is still the coating capacitance, $R_{\text {po }}$ models the resistance or ionically conducting path across the coating ("pores" or defects) 

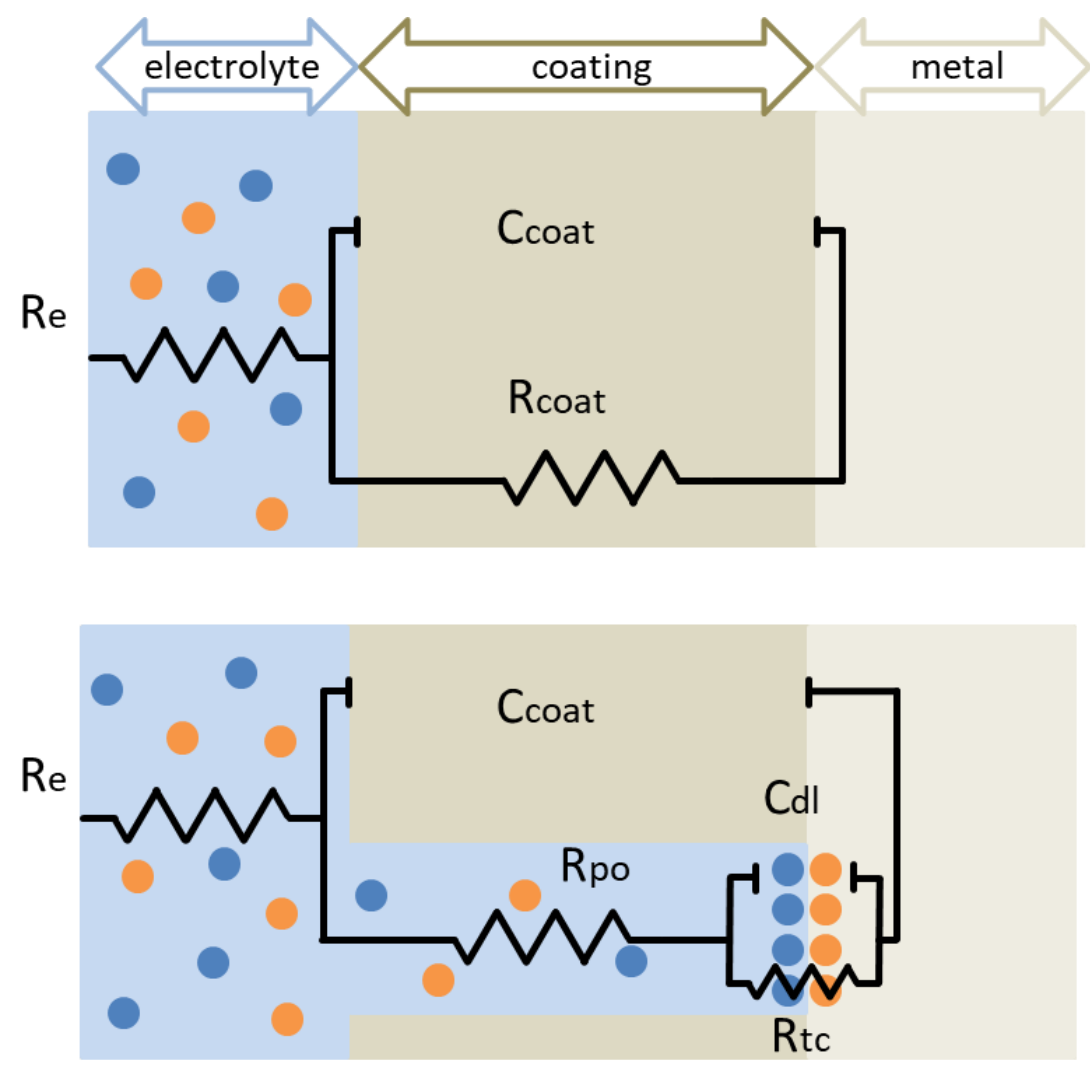

Figure 3 Scheme of typical equivalent circuits in a coating-metal system.

Each of these elements as well as its position in the circuit shows a characteristic feature in the EIS spectra. Figure 4 shows four common equivalent circuits and their characteristic appearance both in the Bode and Nyquist plot.

Figures $4 \mathrm{a}$ and $4 \mathrm{~b}$ present at typical EIS spectra of the systems depicted in Figure 3. Figure 4c present a defective coating response, similar to $4 \mathrm{~b}$, in which the capacitors are replaced by CPE, producing a characteristic depress of the semicircles in the Nyquist plot. A typical circuit modelling diffusive process is shown in Fig. 4d. producing a distinctive $45^{\circ}$ tail in the low-frequency region of the Nyquist plot. 

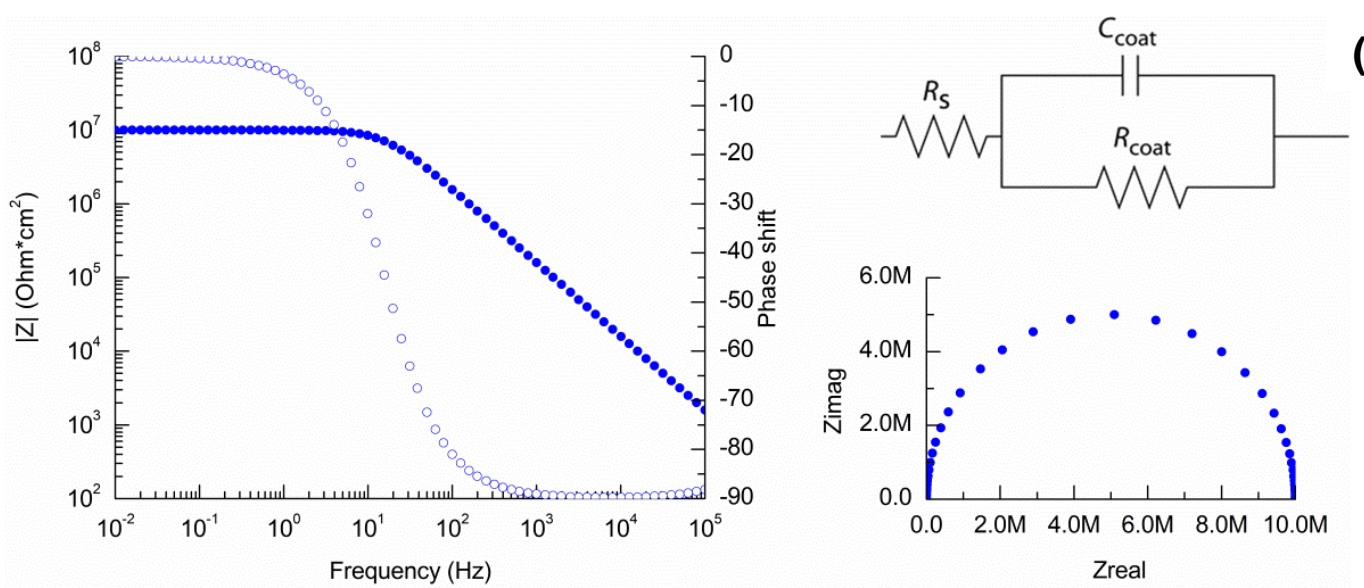

(a)
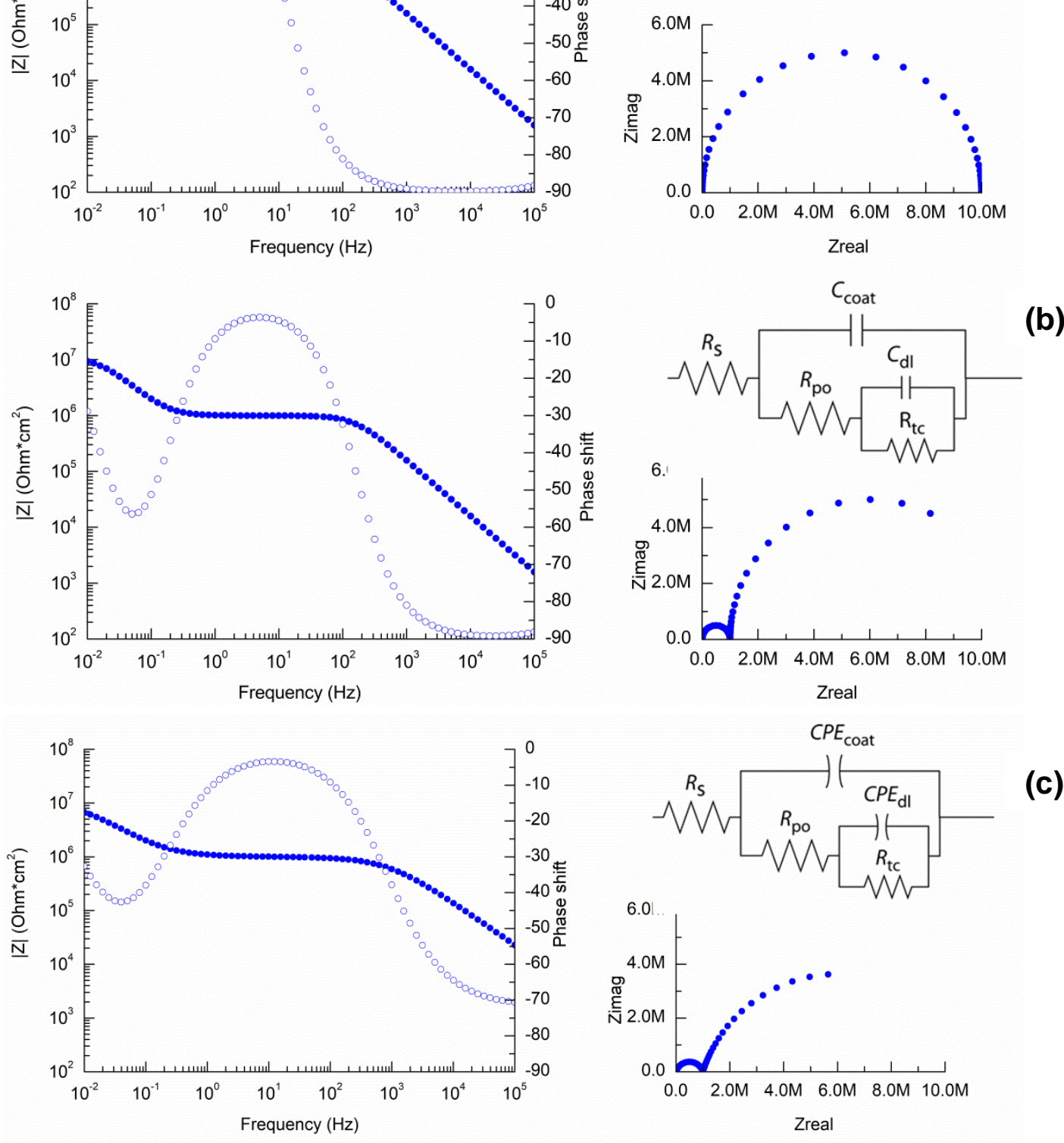

(c)
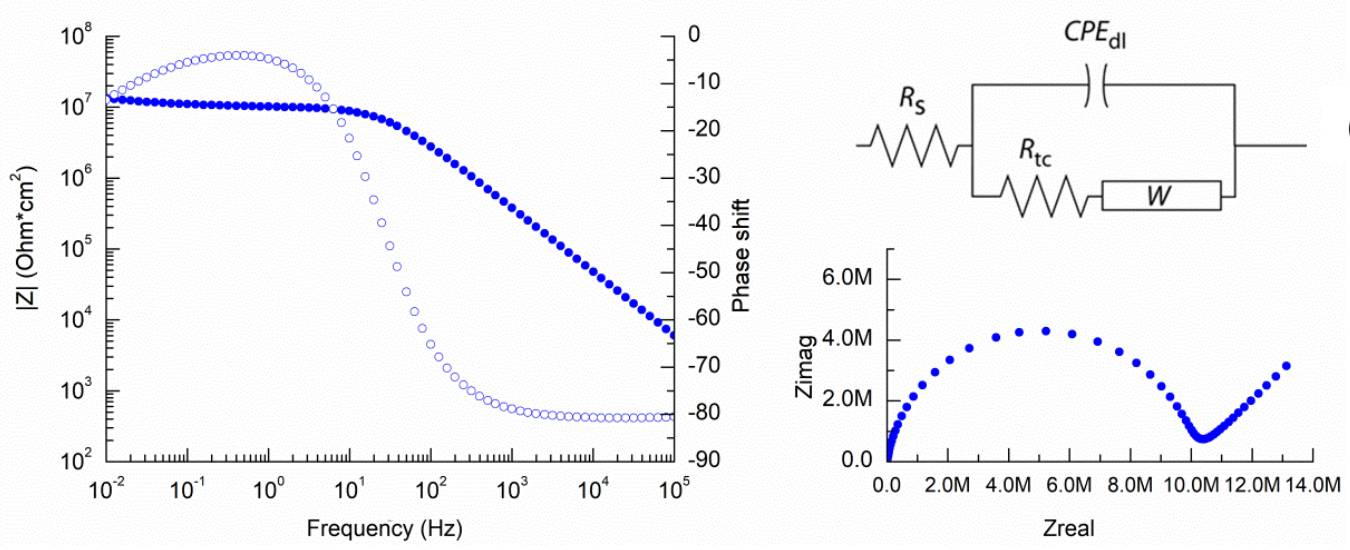

(d)

Figure 4 Bode and Nyquist plots of different equivalent circuits. 


\section{Experimental setup}

\subsection{Electrochemical cell}

EIS experiments for corrosion studies are normally carried out with a classical 3-electrode electrochemical cell, with a reference electrode (RE) as reference for electrochemical potential, a counter electrode (CE) which is an inert electrode to close the circuit, and the working electrode(WE) being the material under study. The most common RE are SCE or $\mathrm{Ag} / \mathrm{AgCl}$, while the CE is made of a bar, wire or mesh of an inert material (platinum, graphite, stainless steel...).

According to the object of study, traditional cells usually adopt two different configurations: immersion cell and flat cell. In the immersion cell the object is placed inside the cell, submerged in the electrolyte: while the flat cell is fixed to the (flat) surface of the metal, exposing only a limited area of the WE to the electrolyte. In these cells, different aqueous electrolytes can be used in order to simulate real environment conditions. The most common ones for cultural heritage studies are $\mathrm{NaCl} 0.1 \mathrm{M}$, Harrison electrolyte $\left(0.35 \%\left(\mathrm{NH}_{4}\right)_{2} \mathrm{SO}_{4+} 0.05 \%\right.$ $\mathrm{NaCl}$ ), mineral water [2], $\mathrm{K}_{2} \mathrm{SO}_{4} 0.25 \mathrm{M}$ [3] and acetic acid [4]. Although for laboratory tests the selection of the electrolyte relies on the nature of metal/environment interaction under study, when working on real heritage objects, it is mandatory to use mild electrolytes, in order to avoid any damage to the surface. For this purpose, mineral water or mild artificial rain are adequate choices [5].

Immersion cell and flat cells have been used in laboratory studies to evaluate waxes, oils and coatings $[3,6,7]$ for metallic heritage protection on flat samples, usually artificially produced coupons that try to mimic the surface of actual artifacts. Nevertheless, these conventional setups are not suitable for large objects or in situ measurements on the irregular surfaces of sculptures and monuments.

\subsection{Electrochemical techniques in-situ}

To overcome the difficulties in field measurements three basic approaches have been proposed: trying to fix a traditional-like cell to the monument surface [8], retaining the liquid electrolyte absorbed in a cloth or sponge [2, 9] or using a solid gel electrolyte $[10,11]$. Some designs have given acceptable results and are being further developed while others have been soon abandoned.

First portable cell specifically tailored to electrochemical measurements on metallic heritage was designed by Paola Letardi [2]. She proposed a contact cell constructed with two concentric AISI 316 stainless steel electrodes embedded in a PTFE cylinder, which act as CE and RE. The electrolyte is supported by a cloth attached to the basis of the cylinder. To avoid drying, it is connected to a small electrolyte reservoir (Figure 5). This cell has shown to be an effective device for EIS measurements, and has been used in different studies [12-15]. Nevertheless 
it still has the inconvenience of handling the liquid electrolyte, and the rigidity of the cell limits its adaption to surfaces.

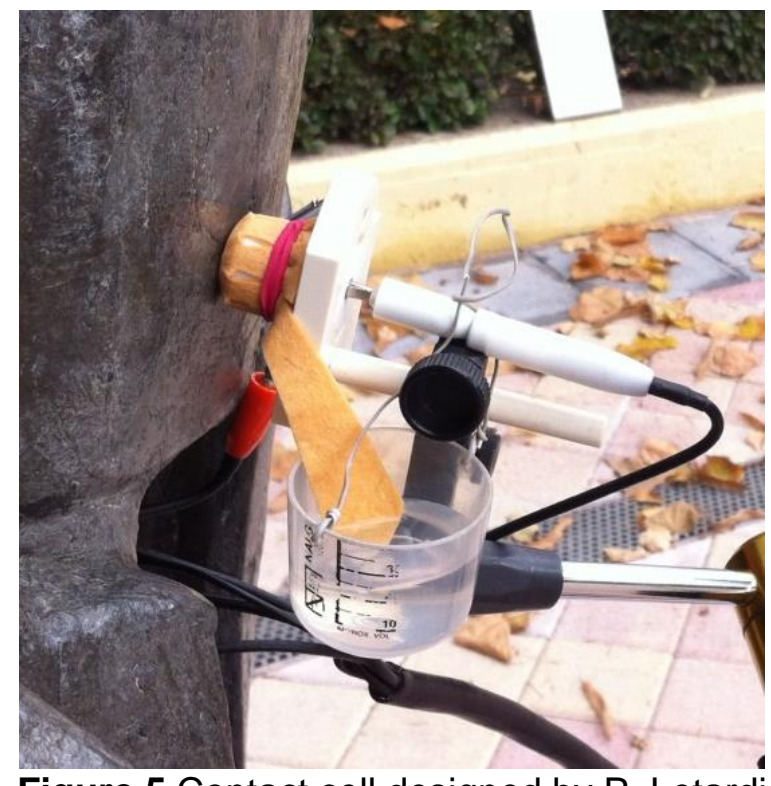

Figure 5 Contact cell designed by P. Letardi

Researchers from the Politecnico di Torino have been working in the design of a complete portable system for in situ measurements [8]. Although their main contribution is in the design of low-cost instruments for corrosion studies, they have also explored different cell setups both with liquid and solid electrolytes, including commercial electrocardiogram (ECG) electrodes [16, 17]. The use of gel electrodes such as those for ECG represents an interesting solution to overcome the inconveniences of handling liquid electrolytes in field measurements. Unfortunately, it is not that simple and commercial ECG electrodes have shown different problems, introducing distortions in measurements due to low conductivity and inhomogeneity in the gel thickness [16]. Clare and coworkers have explored further possibilities of this approach by developing/optimizing the gel formulation. These gel electrodes are based on AMPS/PAA (2-acrylamido-2-methyl-propanesulfonic acid/ polyacrylic acid) copolymers [10,18], equilibrated with different electrolytes. Besides modifications in the gel formulation, Clare and coworkers propose the use of a double cell setup, separating the RE and CE from the WE contact. This would allow electrochemical measurements without the need of physical contact with the metal surface under the coating. Nevertheless, this cell has also two main drawbacks, the limited options for the electrolyte, as it is determined by the gel, and possible problems in current distribution. 


\section{Gel Polymer Electrolyte (G-PE) Cell}

As an alternative to previously described systems we propose the use of a traditional electrolyte gelled with agar [19]. A small amount of agar is dissolved in a liquid electrolyte, poured inside the cell and left to cool. When the agar solidifies, the cell cap is removed leaving a protruding gel cylinder which is placed in contact with the surface under study. The effect of using an agar gelled electrolyte has been carefully studied [11], showing that there is an increase electrolyte conductivity, and a slightly increase in the anodic reaction rate (when used in concentrations above 3\%). Despite these effects, agar does not affect the corrosion mechanisms, thus can be used for comparative studies.

Figure 6 shows the construction and use of the G-PE cell. The cell follows the conventional three-electrode design. The reference electrode and the counter electrode are fixed in a two-piece plastic mold. An AISI316 stainless steel wire is used as a pseudo-reference electrode, and the CE is made of an AISI316 stainless steel mesh. Different RE and CE electrodes and cell geometries have been tested to optimize the cell design and minimize possible artifacts from the setup [20, 21].

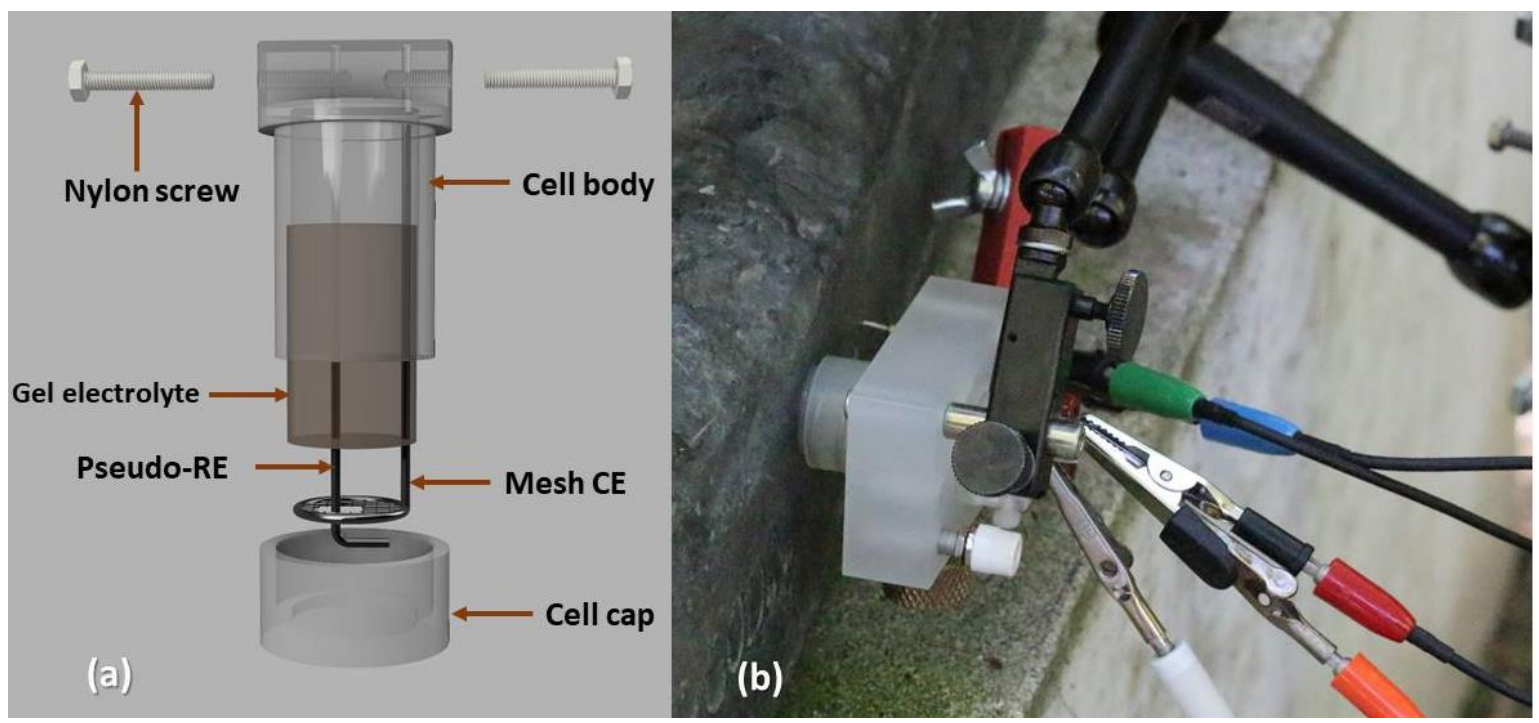

Figure 6 G-PE cell design and in-situ application.

This cell provides several advantages for in situ EIS measurements. The use of a solid electrolyte allows measuring in any position, and the flexibility of the gel can adapt to surface irregularities. Besides, agar is a cheap and easy to handle material, and allows using a wide range of aqueous solutions as electrolyte. Finally, although a pseudo-reference electrode may be more convenient for field measurements, a real reference electrode can be used [21].

This cell has been validated in laboratory studies to assess the loss of protective properties of coatings for bronze. Figure 7 shows an example of the 
EIS spectra of three traditional coatings used in conservation of metallic heritage applied on bronze coupons, Incralac, Paraloid B72 and Cosmolloid H80, and how changes in their protective properties can be measured using EIS and the G-PE cell after a brief outdoor exposure [22].
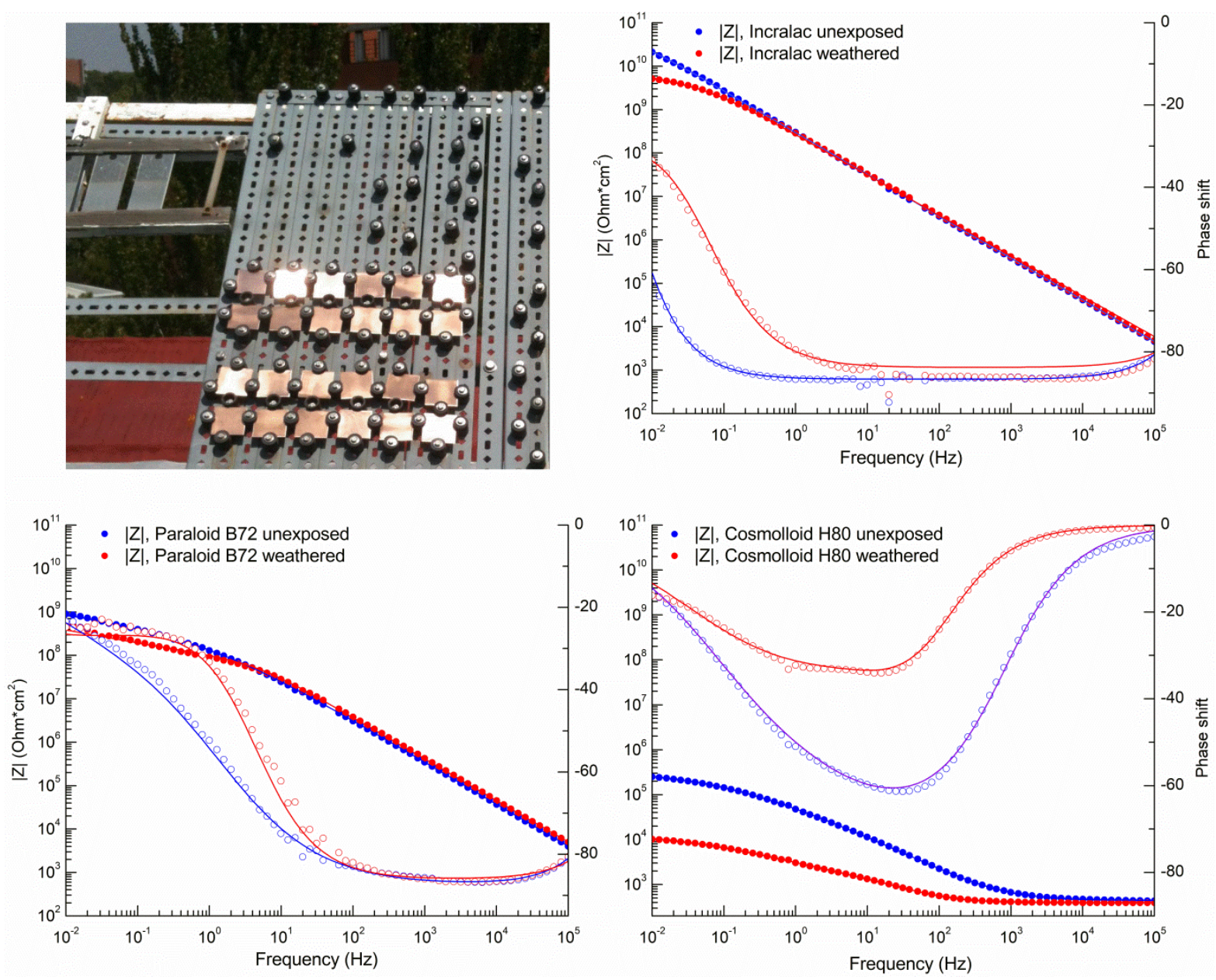

Figure 7 EIS spectra of Incralac, Paraloid B72 and Cosmolloid H80 over bronze coupons, after preparation (blue) and a short atmospheric exposure (red) [22].

Coating degradation has also been measured on outdoor bronze sculpture. The conservation treatment of the bronze sphinxes at the National Archaeological Museum has been followed in situ by means of the G-PE cell [23]. The corrosion resistance of two areas of one of the sphinxes, one with a green patina (GP) and one with a dark patina (DP) was measured and compared before and after the treatment, and the evolution of the Incralac coating which was applied, followed over time. 


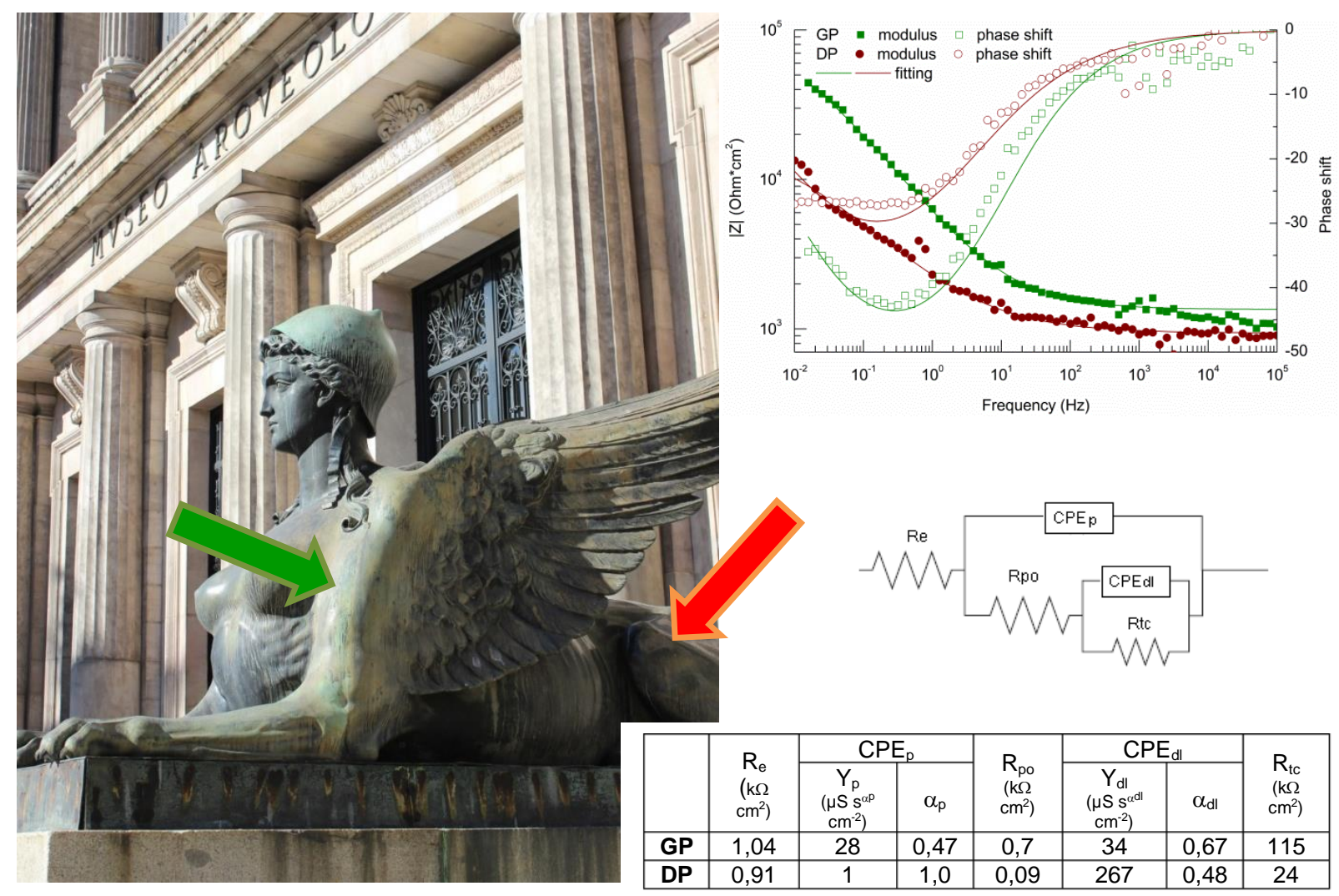

Figure 8 EIS study of a bronze sphinx at the National Archaeological Museum of Spain. The EIS spectra of the selected green and dark areas of the patina showed that the green patina was about five times more protective than the dark one.

The G-PE has also shown to be very useful to the study of weathering (Cor-Ten) steel surfaces, which are can be highly textured and porous. Differences in corrosion resistance of artificial patinas have been evaluated using this cell [24], showing that chemical treatments applied by artists to accelerate the patination of weathering steel reduce the corrosion resistance. Field studies have also shown that it is possible to appreciate significant differences in different areas of the same sculpture, which is of relevance for the establishment of an adequate conservation protocol [25-27].

\section{Conclusions}

Electrochemical techniques in general, and specially EIS, can provide quantitative and qualitative information on the corrosion processes responsible for the degradation of the metallic cultural heritage and the protective properties of coatings and other systems employed in the conservation treatments.

In many cases, these studies need to be carried out in-situ, on the surface of the real artifacts. Several approaches have been proposed by heritage scientist to tackle the practical issues of these in-situ measurements. A gel-polymer electrolyte electrochemical cell (G-PE), specifically tailored for cultural heritage, has been developed by our research group. This cell allows in situ 
electrochemical tests on metallic cultural heritage, where the use of traditional cells is not possible. It has been proved to provide relevant information for the conservation assessment, giving good results both in laboratory samples and field measurements.

\section{Acknowledgements}

This work has been funded by EU project "Integrated Platform for the European Research Infrastructure on Cultural Heritage" (IPERION-CH, Ref. H2020-INFRAIA-2014-2015, GRANT n 654028), by project HAR2014-54893-R from the Ministerio de Economía, Industria y Competitividad (MINECO, Spain), and by Programme GEOMATERIALES 2-CM (S2013/MIT_2914) from the Community of Madrid. Authors also acknowledge the support by the Spanish Network TechnoHeritage, the Museo Arqueológico Nacional and Museo de Escultura de Leganés.

\section{References}

[1] E. Cano, D. Lafuente, D.M. Bastidas, Use of EIS for the evaluation of the protective properties of coatings for metallic cultural heritage: A review, Journal of Solid State Electrochemistry, 14 (2010) 381-391.

[2] P. Letardi, A. Beccaria, M. Marabelli, G. D'Ercoli, Application of electrochemical impedance measurements as a tool for the characterization of the conservation and protection state of bronze works of art, in: J. Ashton, D. Hallam (Eds.) Metal 98. International Conference on Metal Conservation James \& James, Draguignan-Figanières (France), 1998, pp. 303-308.

[3] D. Hallam, A. Thurrowgood, V. Otieno-Alego, D. Creagh, An EIS Method for assessing thin oil films used in museums, in J. Ashton, D. Hallam (Eds.): Metal 04: Proceedings of the International Conference on Metals Conservation, Canberra, Australia, 2004, pp. 388-399.

[4] M. Dowsett, A. Adriaens, B. Schotte, G. Jones, L. Bouchenoire, Real time spectroelectrochemical growth and corrosion resistance monitoring of lead carboxylate coatings in an environmental cell (eCell), in: C. Degrigny, R. van Langh, I. Joosten, B. Ankersmit (Eds.) Metal 07: interim meeting of the ICOM-CC Metal WG. Volume 3, Rijksmuseum, Amsterdam, Netherlands, 2007, pp. 26-31.

[5] P. Letardi, Electrochemical measurements in the conservation of metallic heritage artefacts: An overview, in P. Dillmann, D.Watkinson, E.Angelini, A. Adriaens (Eds): Corrosion and Conservation of Cultural Heritage Metallic Artefacts, EFC Series, Woodhead Publishing, 2013, pp. 126-148.

[6] C. Price, D. Hallam, G. Heath, D. Creagh, J. Ashton, An electrochemical study of waxes for bronze sculpture, in: I.D. MacLeod, S.L. Pennec, L. Robbiola (Eds.) Metal 95. International Conference on Metal Conservation James \& James, Semur-en-Auxois (France), 1995, pp. 233-241. 
[7] E. Cano, D.M. Bastidas, V. Argyropoulos, S. Fajardo, A. Siatou, J.M. Bastidas, C. Degrigny, Electrochemical characterization of organic coatings for protection of historic steel artefacts, Journal of Solid State Electrochemistry, 14 (2010) 453-463.

[8] E. Angelini, A. Carullo, S. Corbellini, F. Ferraris, V. Gallone, S. Grassini, M. Parvis, A. Vallan, Handheld-impedance-measurement system with seven-decade capability and potentiostatic function, IEEE Transactions on Instrumentation and Measurement, 55 (2006) 436-441.

[9] B. Elsener, M. Alter, T. Lombardo, M. Ledergerber, M. Wörle, F. Cocco, M. Fantauzzi, S. Palomba, A. Rossi, A non-destructive in-situ approach to monitor corrosion inside historical brass wind instruments, Microchemical Journal, 124 (2016) 757-764.

[10] T.L. Clare, A. England, N. Swartz, K. Hosbein, Onsite electrochemical monitoring method for early detection of coating failure, in: E. Hyslop, V. Gonzalez, L. Troalen, L. Wilson (Eds.): Metal 2013 : proceedings of the interim meeting of the ICOM-CC Metal Working Group, Edinburgh, 2013, pp. 89-94.

[11] B. Ramírez Barat, E. Cano, The use of agar gelled electrolyte for in situ electrochemical measurements on metallic cultural heritage, Electrochimica Acta, 182 (2015) 751-762.

[12] D. Gulotta, B. Mariani, E. Guerrini, S. Trasatti, P. Letardi, L. Rosetti, L. Toniolo, S. Goidanich, Mi Fuma il Cervello self-portrait series of Alighiero Boetti: Evaluation of a conservation and maintenance strategy based on sacrificial coatings, Heritage Science, 5 (2017).

[13] P. Letardi, Laboratory and field tests on patinas and protective coating systems for outdoor bronze monuments, in J. Ashton, D. Hallam (Eds.): Metal 04: Proceedings of the International Conference on Metals Conservation, Canberra, Australia, 2004, pp. 379-387.

[14] P. Letardi, B. Salvadori, M. Galeotti, A. Cagnini, S. Porcinai, A. Santagostino Barbone, A. Sansonetti, An in situ multi-analytical approach in the restoration of bronze artefacts, Microchemical Journal, 125 (2016) 151-158.

[15] A. Sansonetti, M. Colella, P. Letardi, B. Salvadori, J. Striova, Laser cleaning of a nineteenth-century bronze sculpture: In situ multi-analytical evaluation, Studies in Conservation, 60 (2015) S28-S33.

[16] S. Corbellini, M. Parvis, S. Grassini, Noninvasive solution for electrochemical impedance spectroscopy on metallic works of art, IEEE Transactions on Instrumentation and Measurement, 61 (2012) 1193-1200.

[17] S. Grassini, E. Angelini, M. Parvis, M. Bouchar, P. Dillmann, D. Neff, An in situ corrosion study of Middle Ages wrought iron bar chains in the Amiens Cathedral, Applied Physics A: Materials Science and Processing, 113 (2013) 971-979. 
[18] A.H. England, T.L. Clare, Synthesis and characterization of flexible hydrogel electrodes for electrochemical impedance measurements of protective coatings on metal sculptures, Electroanalysis, 26 (2014) 10591067.

[19] E. Cano, A. Crespo, D. Lafuente, B. Ramírez Barat, A novel gel polymer electrolyte cell for in-situ application of corrosion electrochemical techniques, Electrochemistry Communications, 41 (2014) 16-19.

[20] P. Letardi, B. Ramírez Barat, E. Cano, Analysis of the influence of the electrochemical cell setup for corrosion measurements on metallic cultural heritage, in: European Corrosion Congress - EUROCORR, Prague, 2017.

[21] B. Ramírez Barat, E. Cano, P. Letardi, Advances in the design of a gel-cell electrochemical sensor for corrosion measurements on metallic cultural heritage, Sensors and Actuators B: Chemical, 261 (2018) 572-580.

[22] B. Ramírez Barat, E. Cano Díaz, In situ assessment of protective coatings for metallic cultural heritage using electrochemical impedance spectroscopy, Ge-Conservacion, 2015 (2015) 6-13.

[23] B. Ramírez Barat, A. Crespo, E. García, S. Díaz, E. Cano, An EIS study of the conservation treatment of the bronze sphinxes at the Museo Arqueológico Nacional (Madrid), Journal of Cultural Heritage, 24 (2017) 93-99.

[24] B. Ramírez Barat, T. Palomar, B. Garcia, D. De la Fuente, E. Cano, Composition and Protective Properties of Weathering Steel Artificial Patinas for the Conservation of Contemporary Outdoor Sculpture, in: 9th interim meeting of the ICOM-CC Metals Working Group. METAL2016, New Delhi, India, 2016.

[25] A. Crespo, B. Ramírez Barat, E. Cano, Artificial patinas in contemporary weathering steel sculpture, in: 5th INTERNATIONAL CONFERENCE YOuth in COnservation of CUltural Heritage- YOCOCU 2016, Madrid, 2016.

[26] A. Crespo, B. Ramírez Barat, I. Diaz, E. Cano Díaz, Assessment of the protective properties of patinas on contemporary sculpture made out of weathering steel, in: J. Bridgland (Ed.) ICOM-CC 18th Triennial Conference Copenhagen,, 2017.

[27] B. Ramírez Barat, A. Crespo, E. Cano, In situ evaluation of outdoor sculpture with a gel polymer electrolyte cell, in: TechnoHeritage 2017, CRC Press/Balkema, Cadiz, 2017, pp. (in press). 